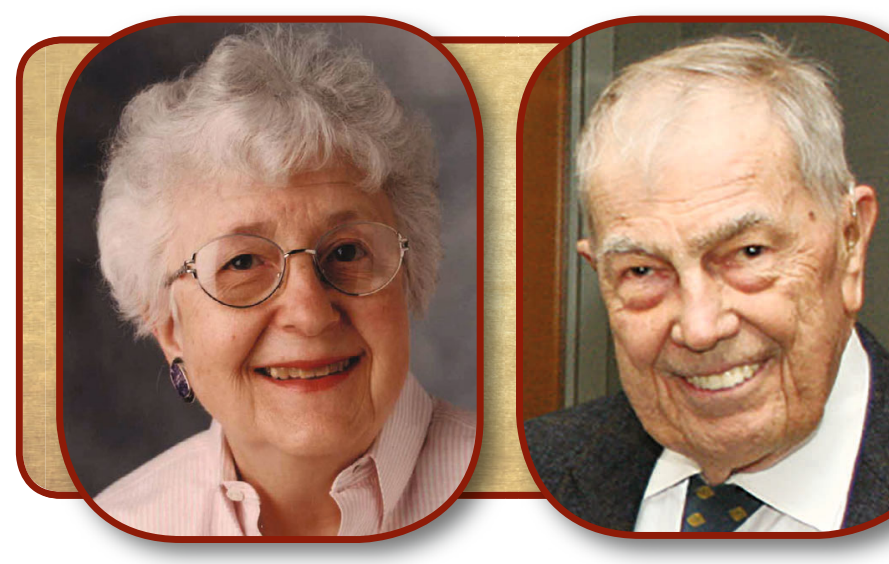

The TMS family lost two pioneers and collective mentors this year in Julia R. Weertman and Johannes (Hans) Weertman, Walter P. Murphy Professors Emerita and Emeritus of Materials Science and Engineering at Northwestern University. Julia passed away at age 92 on July 31, and Hans passed away at age 93 on October 13. The Northwestern McCormick School of Engineering held the Johannes and Julia R. Weertman Symposium \& Remembrance event featuring scientific talks and personal stories from colleagues and friends on November 16 to honor their legacy.

Their lives together began as graduate students at the Carnegie Institute of Technology (now Carnegie Mellon University), where Julia was the first woman admitted to the Institute's College of Science and Engineering. Following their marriage, they then travelled to Paris, France, to pursue postdoctoral studies as Fulbright Fellows at École Normale Supérieure, and then returned to the United States to work at the Naval Research Laboratory. Recalled David N. Seidman, a friend and colleague from Northwestern University, "Hans commenced working on high-temperature creep of metals, which paved the way to his working in the field of glaciology and provided an explanation of how glaciers flow: he has an island named after him in Antarctica."

Next, Hans joined Northwestern as an associate professor of materials science and engineering and later a professor of geophysics, while Julia focused on raising their two children. After 13 years, Julia joined Hans at Northwestern as an assistant dean of the McCormick School of Materials and Applied Science. She then served as assistant professor of materials science and engineering and eventually became chair of the department - the first woman in the United States to do so.

Among their many accomplishments, they have both been elected to the National Academy of Engineers, and inducted as fellows of the American Academy of Arts and Sciences, ASM International, the American Physical Society, and the American Geophysical Union. Within TMS, they were both honored for their outstanding contributions to the field by elevation to the Class of Fellow-Hans in 1990 and Julia in 1993, making Julia the Society's first female Fellow. Julia was also the recipient of the 2014 John Fritz Medal

\section{Remembering Julia and Hans Weertman}

\author{
Kaitlin Calva
}

from the American Association of Engineering Societies (for which TMS nominated her via the American Institute for Mining, Metallurgical, and Petroleum Engineers), and TMS's 2015 Ellen Swallow Richards Diversity Award. In 2017, the TMS Educator Award was renamed the Julia and Johannes Weertman Educator Award to honor both their individual and joint accomplishments, as well as their pioneering research and instrumental roles in the emergence of materials science and engineering as a discipline.

Beyond technical and professional excellence, the couple served as advisors to nearly $60 \mathrm{Ph}$.D. students and 15 postdoctoral researchers and visiting scholars, and mentored countless more individuals. To quote Julia in her profile for the National Academy of Engineering's EngineerGirl website: "My prides and joys are my former students, who have gone on to careers of high achievement in engineering."

Read on for more heartfelt words of admiration from colleagues, friends, and those who knew Julia and Hans best.

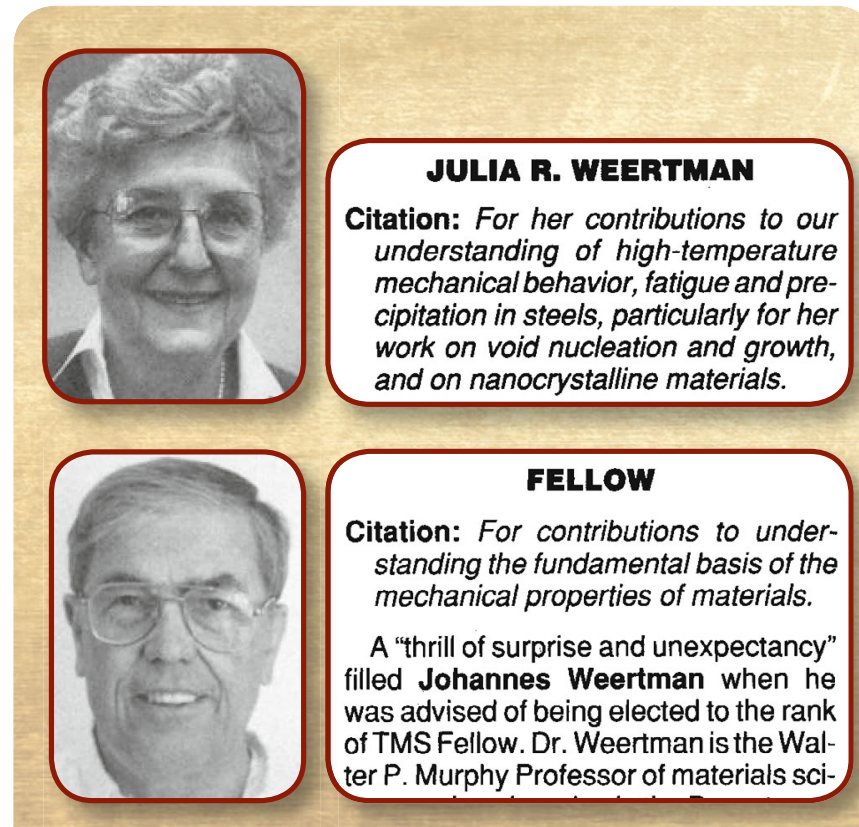

The excerpts above show Fellow Award citations for Hans and Julia as they were originally printed in the March 1990 (bottom) and February 1993 (top) issues of TMS News in $J O M$, respectively. 


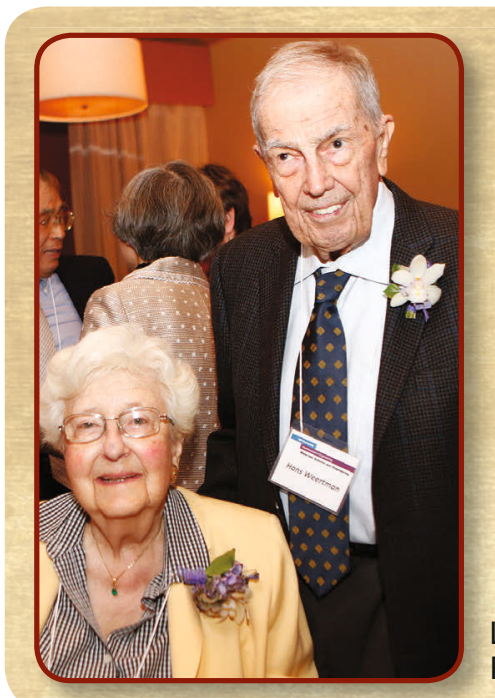

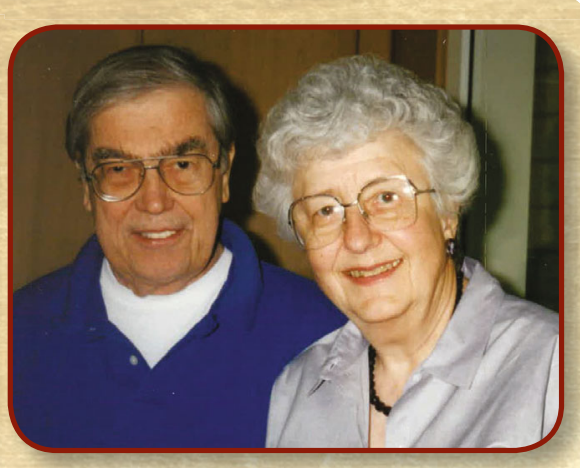

Above: Julia and Hans at a 70th birthday celebration for Julia. Photo credit: Northwestern University

Left: Julia and Hans Weertman.

Photo credit: Jasmin Shah
"Hans and Julia Weertman were family to all those in the global materials community. Their legacy of devotion to science and their support for all scientists will be greatly missed. Hans and Julia were also good friends, the best kind of friends who were always available and open and willing to cheer you up no matter what. I feel very privileged for the two decades plus that I spent as their friend, for our many trips together, and for all the wonderful discussions about materials. What I will remember most was all the fun we had and how every time I came to visit, I felt right at home. Hans and Julia, I love you both and will miss you dearly."

-Andrea M. Hodge, Vice Provost for Undergraduate Programs and Arthur B. Freeman Professor, University of Southern California
"The scientific community has lost two giants, two leaders in both basic science and the broad impact associated with them being extraordinary human beings: among many achievements, Julia was the first female materials science and engineering department chair in the country and she trail-blazed the discipline of nanostructured metals; Hans made a foundational impact in the area of dislocations, and was highly interdisciplinary, well before that word was in vogue, crossing over from materials to mechanics to geology."

—David Dunand, Professor of Materials Science and Engineering, Northwestern University

"In her more than 60-year career, Julia served as an inspiration to generations of materials scientists through her scholarship on creep and nanomaterials, her professional service to TMS and the greater materials community, and her mentoring and support of students and faculty."

-Katherine Faber, Simon Ramo Professor of Materials Science, California Institute of Technology

"Julia Weertman was a tremendously talented and inspirational member of the materials science and engineering community, not only in the U.S. but around the world. Her science was groundbreaking, especially in the area of nanocrystalline and nanotwinned materials, and she was a highly sought out collaborator. Julia had high standards and demanded first-rate science, but she was also very generous with her time and always willing to talk with and mentor young people. I feel very fortunate to have known her and to have become one of her extended mentees. Julia Weertman was such a fabulous role model for all of us, and the special relationship and life that she shared with her husband, Hans, was truly magical. The life that they shared called all that knew them to not only be pioneering researchers but also to live a full life that extended well beyond the laboratory. They were such pioneers and they will be deeply missed."

-Kevin Hemker, 2018 TMS President; Alonzo G. Decker Chair and Professor of Mechanical Engineering at Johns Hopkins University
"I met Hans personally as a young professor at New Mexico Tech. His mind had an uncanny reach and tremendous ability to transform vague concepts into analytical formulations that I have followed for 50 years. He made seminal contributions to glaciology, the creep of metals and planetary mountains, and many other areas of materials science. I met Julia, the 'grand dame' of materials science, some years later. She was an extraordinary person who melded a sharp intellect with a genteel approach. She had a great influence on many foundational aspects of the field. The loss of these twin giants in materials science should serve as an inspiration for the younger generations to pursue study and to continue to explore the boundaries of knowledge. While we lose two great mentors, we are grateful for the fact that they have enriched our lives and have the certainty that they will continue to provide a guiding light through the turbulence of our lives."

-Marc Andre Meyers, Distinguished Professor in Materials Science, University of California, San Diego

"I have known Hans and Julia Weertman for over 33 years, first as their colleague and then as their friend. Hans and Julia were a model couple for many people as living proof that a marriage between two accomplished materials scientists can work, and work very well indeed. Julia was very generous with her time in nominating her colleagues for different scientific and engineering honors. Hans was a very modest person and I never heard him brag, even once, about his many scientific accomplishments and awards, and the same is true of Julia. It was evident the great affection that Hans had for Julia."

-David N. Seidman, Walter P. Murphy Professor of Materials Science and Engineering, Northwestern University

"Julia Weertman was an inspiration and role model for me in so many ways, from her pioneering research to her leadership in the community and the outstanding mentorship of her students."

-Peter W. Voorhees, Frank C. Engelhart Professor, Northwestern University 